\title{
Comparison of a disposable sorptive sampler with thermal desorption in a gas chromatographic inlet, or in a dedicated thermal desorber, to conventional stir bar sorptive extraction-thermal desorption for the determination of micropollutants in water
}

Madelien Wooding, Egmont R. Rohwer, Yvette Naudé*

Department of Chemistry, University of Pretoria, Private Bag X20, Hatfield 0028, Pretoria, South Africa *Corresponding author. Tel.: +27 12420 2517; fax: +27 12420 4687; yvette.naude@up.ac.za.

\section{Highlights}

- Low cost (less than 1 USD) disposable/reusable PDMS sorptive loop sampler.

- Direct thermal desorption of sampler in GC inlet of 2DGC-TOFMS, cryogenics not required.

- Comparison of the loop sampler to commercial stir bar sorptive extraction.

- Comparison of thermal desorption in a GC inlet to a dedicated thermal desorber.

\section{ABSTRACT}

The presence of micropollutants in the aquatic environment is a worldwide environmental concern. The diversity of micropollutants and the low concentration levels at which they may occur in the aquatic environment have greatly complicated the analysis and detection of these chemicals. Two sorptive extraction samplers and two thermal desorption methods for the detection of micropollutants in water were compared. A low-cost, disposable, in-house made sorptive extraction sampler was compared to SBSE using a commercial Twister sorptive sampler. Both samplers consisted of polydimethylsiloxane (PDMS) as a sorptive medium to concentrate micropollutants. Direct thermal desorption of the disposable samplers in the inlet of a GC was compared to conventional thermal desorption using a commercial thermal desorber system (TDS). Comprehensive gas chromatography coupled to time-of-flight mass spectrometry (GC×GC-TOFMS) was used for compound separation and identification. Ten micropollutants, representing a range of heterogeneous compounds, were selected to evaluate the performance of the methods. The in-house constructed sampler, with its associated benefits of low-cost and disposability, gave results comparable to commercial SBSE. Direct thermal desorption of the disposable sampler in the inlet of a GC 
eliminated the need for expensive consumable cryogenics and total analysis time was greatly reduced as a lengthy desorption temperature programme was not required. Limits of detection for the methods ranged from $0.0010 \mathrm{ng} \mathrm{L}^{-1}$ to $0.19 \mathrm{ng} \mathrm{L}^{-1}$. For most compounds, the mean $(n=3)$ recoveries ranged from $85 \%$ to $129 \%$ and the $\%$ relative standard deviation (\% RSD) ranged from $1 \%$ to $58 \%$ with the majority of the analytes having a \%RSD of less than $30 \%$.

Keywords: Disposable PDMS sampler; SBSE; Micropollutants; Water; GCxGC-TOFMS; Thermal desorption

\section{Introduction}

Micropollutants, also referred to as emerging contaminants, comprise of an ever expanding range of anthropogenic and natural substances [1]. The presence of micropollutants, such as pharmaceuticals, personal care products (PCPs), steroid hormones, industrial chemicals, pesticides and endocrine disrupting chemicals (EDCs), in the aquatic environment is a worldwide environmental concern [1, 2]. Long- and short-term toxicity of drinking water, endocrine disrupting effects and antibiotic resistance of microorganisms are some of the examples of the adverse effects associated with emerging contaminants in the aquatic environment [2]. The diversity of micropollutants and the low concentrations $\left(\mu \mathrm{g} \mathrm{L}^{-1}\right.$ to $\left.\mathrm{ng} \mathrm{L}^{-1}\right)$ at which they occur in aquatic systems have significantly complicated analyses of these chemicals [1,2]. Water quality standards and contaminant guidelines do not exist for the majority of micropollutants, due to the challenges posed by the analysis and detection thereof [1]. However, recent advances in analytical chemistry and instrumentation have enabled the detection of vast ranges of micropollutants at trace level, resulting in increased public awareness and facilitation of the legislation process [2].

Currently, the most common extraction technique used for monitoring micropollutants in environmental water samples is solid phase extraction (SPE) employed together with gas chromatography (GC) or liquid chromatography (LC) coupled to mass spectrometry (MS) or tandem mass spectrometry (MS/MS) [2, 3]. However, new, efficient and inexpensive analytical methods are necessary for on-going environmental monitoring and evaluation [4]. Several research groups have 
shifted their focus from adsorbents, such as SPE, to another class of materials, namely sorption materials [5]. Combining sample extraction, purification, and enrichment, using approaches such as solid phase microextraction (SPME) and stir bar sorptive extraction (SBSE), has moved sample preparation towards a more "green", i.e. solvent free, approach [6]. SPME and SBSE are commercial solvent free sorptive extraction techniques. SPME was introduced in 1990 by Arthur and Pawliszyn [7] to address the need for rapid sample preparation in the laboratory and on-site [8]. The potential sensitivity drawback due to low sorptive volumes of SPME samplers was overcome with the introduction of SBSE (developed by Baltussen and Sandra in 1999) [9]. Polydimethylsiloxane (PDMS) is currently the most popular sorbent material. It is an apolar $100 \%$ methyl substituted siloxane polymer [5]. The popularity of PDMS is due to its: (1) inertness, therefore reducing analyte loss due to irreversible adsorption or catalytic (surface) reactions, (2) retention data for many compounds are widely available, (3) PDMS synthesis is moderately simple leading to reproducible properties and consistency between manufacturers, and (4) the degradation products are well known and can easily be identified by mass spectrometry [5]. Various researchers have employed the advantages of PDMS to develop new samplers. Triñanes, Pena, Casais and Mejuto (2015) developed disposable silicone disks for the detection of polyaromatic hydrocarbons (PAHs) in water samples [10]. Naudé and co-workers developed a PDMS loop sampler for solvent free extraction of soil $[11,12]$. The same sampler was also used by Naudé et al. (2015) as a passive sampler to concentrate pollutants from surface water [13]. Recently, the loop sampler was used to quantitatively extract endocrine disrupting compounds (EDCs) from surface water [14]. When developing customized samplers the use of bulk, relatively inexpensive, PDMS gives the user control over the choice of sorbent volume and preparation of application specific sorptive samplers. The low cost of the sorbent material allows the employment of a new sampler for each extraction thereby avoiding difficulties with carry-over and cross contamination [10]. The hydrophobicity of PDMS enables high recovery of hydrophobic compounds. In order to increase the recovery for polar compounds, Ochiai et al. (2008) developed a sequential salting out extraction procedure for multi-residue analysis [15].

In order to overcome sensitivity shortcomings of liquid extraction techniques, due to the injection of only an aliquot of the extract into the analytical instrument, sorptive sampling techniques coupled to thermal desorption (TD), in combination with GC, are more often being used $[5,16]$. During TD volatile and semi-volatile organic compounds are desorbed from the sorptive material, 
either directly in a heated capillary GC injection port liner [17], or in a stainless-steel or glass tube in a thermal desorber system $[18,19]$. Heat is applied followed by direct introduction of the compounds into the GC injection port via a heated transfer line (in the case of a thermal desorber system). The technique is solvent free and can be automated [20]. Comprehensive two-dimensional gas chromatography $(\mathrm{GC} \times \mathrm{GC})$ is a powerful tool that aids in the determination of a vast number of compounds in a complex matrix during a single analysis [21]. It realizes better resolution (increased selectivity), higher sensitivity and larger peak capacity compared to the conventional one-dimensional GC $[22,23]$. The increased resolving power and enhanced sensitivity make $G C \times G C$ extremely useful in detecting targeted and non-targeted trace-level components in complex samples [24].

We report a comparison of conventional SBSE-thermal desorption to extraction using an inhouse developed, disposable PDMS loop sorptive sampler with thermal desorption thereof directly in the inlet liner of a GC (an approach used by Bicchi, lori, Rubiolo and Sandra (2002) with SBSE [17]), or in a dedicated themal desorber, followed by analysis with comprehensive two-dimensional gas chromatography and time-of-flight mass spectrometry (GC×GC-TOFMS) for the detection of micropollutants in surface water. Ten micropollutants representing diverse classes, including pesticides, personal care products and pharmaceuticals commonly occurring in surface water were selected to evaluate the performance of the methods in terms of linearity, limits of detection (LODs), limits of quantification (LOQs), accuracy and precision.

\section{Materials and methods}

\subsection{Chemicals}

Methanol (MeOH), $n$-hexane, toluene, de-ionised water, acetonitrile (ACN), acetone and sodium chloride $(\mathrm{NaCl})$ were all purchased from Merck, South Africa. Certified reference standards were used. Caffeine solution (1.0 mg mL ${ }^{-1}$ in MeOH), atrazine (PESTANAL, analytical standard, purity $98.8 \%$ ), chlorpyrifos (PESTANAL, analytical standard, purity 99.7 $\%$ ), musk ketone solution (100 $\mathrm{ng} \mu \mathrm{l}^{-1}$ in acetonitrile, analytical standard, $95 \mathrm{ng} \mathrm{LL}^{-1} \pm 5 \%$ ), lindane (PESTANAL, analytical standard, purity $99.8 \%$ ), metolachlor (PESTANAL, analytical standard, purity $97.6 \%$ ), terbuthylazine (PESTANAL, analytical standard, purity $99.4 \%$ ) and bifenthrin (PESTANAL, analytical standard, purity 98.8\%) were all purchased from Fluka 
Analytical, Sigma-Aldrich, South Africa. Terbutryn (purity $98.1 \%$ ) was purchased from Supelco Analytical, Sigma-Aldrich, South Africa. 4-tert-Amylphenol (purity $99.5 \%$ ) was purchased from Dr. Ehrenstorfer, Augsburg, Germany.

Structures of target analytes and corresponding molecular formulas, nominal masses and $\log K_{\mathrm{ow}}$ values are given in Figure 1.

\section{Fragrances}

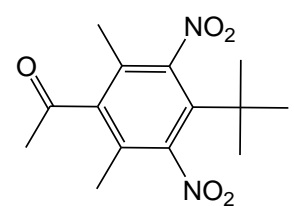

Musk ketone

$\mathrm{C}_{14} \mathrm{H}_{18} \mathrm{~N}_{2} \mathrm{O}_{5}$

Nominal Mass: 294

Log $\mathrm{K}_{\mathrm{ow}}: 3.98$

\section{Pharmaceuticals}<smiles>Cn1c(=O)c2c(ncn2C)n(C)c1=O</smiles>

Caffeine

$\mathrm{C}_{8} \mathrm{H}_{10} \mathrm{~N}_{4} \mathrm{O}_{2}$ Nominal Mass: 194 Log $\mathrm{K}_{\mathrm{ow}}$ : -0.55

\section{Alkylphenols}<smiles>CCC(C)(C)c1ccc(O)cc1</smiles>

4-tert-Amylphenol

$$
\mathrm{C}_{11} \mathrm{H}_{16} \mathrm{O}
$$

Nominal Mass: 164

Log $\mathrm{K}_{\text {ow }}: 3.66$

\section{Pesticides}<smiles>CCOP(=S)(OCC(O)O)Oc1nc(Cl)c(Cl)cc1Cl</smiles>
$\mathrm{C}_{9} \mathrm{H}_{11} \mathrm{Cl}_{3} \mathrm{NO}_{3}$ PS Nominal Mass: 349

Log $\mathrm{K}_{\mathrm{ow}}: 4.78$<smiles>CCNc1nc(Cl)nc(NC(C)(C)C)n1</smiles>

\section{Terbuthylazine} $\mathrm{C}_{9} \mathrm{H}_{16} \mathrm{CIN}_{5}$ Nominal Mass: 229 $\log \mathrm{K}_{\text {ow }}: 2.48$<smiles>CCNc1nc(NC(C)(C)C)nc(SC)n1</smiles>

Terbutryn $\mathrm{C}_{10} \mathrm{H}_{19} \mathrm{~N}_{5} \mathrm{~S}$ Nominal Mass: 241

$\log \mathrm{K}_{\mathrm{ow}}: 2.88$<smiles>Cc1c(COC(=O)C2C(C=C(Cl)C(F)(F)F)C2(C)C)cccc1-c1ccccc1</smiles>

Bifenthrin $\mathrm{C}_{23} \mathrm{H}_{22} \mathrm{CIF}_{3} \mathrm{O}_{2}$ Nominal Mass: 422

$\log \mathrm{K}_{\mathrm{ow}}: 6.59$<smiles>CCc1cccc(C)c1N(C(=O)CCl)C(C)COC</smiles>

Metolachlor $\mathrm{C}_{15} \mathrm{H}_{22} \mathrm{CINO}_{2}$ Nominal Mass: 283 Log $\mathrm{K}_{\mathrm{ow}}: 3.45$

Figure 1. Structures of target analytes with corresponding molecular formulas, nominal masses and log $K_{\text {ow }}$ values. 


\subsection{Standard solutions}

Individual stock solutions of $100 \mathrm{ng} \mathrm{L}^{-1}$ were prepared by dissolving $5 \mathrm{mg}$ powder in $50 \mathrm{~mL}$ (or $2.5 \mathrm{mg}$ powder in $25 \mathrm{~mL}$ ) of methanol or toluene depending on their solubility. All the stock solutions were stored in glass vials and kept at $4{ }^{\circ} \mathrm{C}$. Working standard solutions containing a mixture of the target analytes were prepared at $1 \mathrm{ng} \mathrm{LL}^{-1}$ by combining suitable aliquots of each individual stock solution and diluting it with $n$-hexane to a final volume of 1 $\mathrm{mL}$. Stock solutions purchased in $\mathrm{MeOH}$ required a four-fold dilution with toluene before being miscible with $n$-hexane. Spiking solutions for the matrix matched calibrations were prepared at three different levels of concentration $\left(0.5,0.05\right.$ and $\left.0.01 \mathrm{ng}^{-1}\right)$ by diluting aliquots of the $1 \mathrm{ng} \mathrm{hL}^{-1} n$-hexane solution with acetone (miscible with water) to a final volume of $1 \mathrm{~mL}$. All the working solutions were stored in glass vials and kept at $4{ }^{\circ} \mathrm{C}$.

\subsection{Matrix matched calibrations}

Matrix matched calibration curves of reference compounds were constructed by spiking $50 \mathrm{~mL}$ de-ionized water with the spiking solutions in acetone at concentration levels of

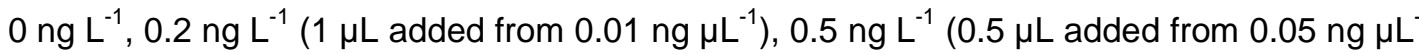

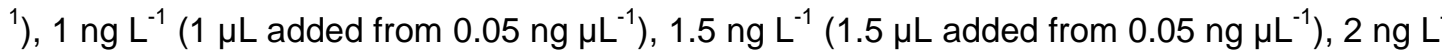

${ }^{1}\left(2 \mu \mathrm{L}\right.$ added from $\left.0.05 \mathrm{ng} \mathrm{\mu L}^{-1}\right), 5 \mathrm{ng} \mathrm{L}^{-1}\left(0.5 \mu \mathrm{L}\right.$ added from $\left.0.5 \mathrm{ng} \mathrm{hL}^{-1}\right), 10 \mathrm{ng} \mathrm{L}^{-1}(1 \mu \mathrm{L}$ added from $\left.0.5 \mathrm{ng} \mathrm{\mu L}^{-1}\right), 20 \mathrm{ng} \mathrm{L}^{-1}\left(2 \mu \mathrm{L}\right.$ added from $\left.0.5 \mathrm{ng} \mathrm{LL}^{-1}\right), 40 \mathrm{ng} \mathrm{L}^{-1}(4 \mu \mathrm{L}$ added from $0.5 \mathrm{ng}^{\mathrm{L}} \mathrm{L}^{-1}$ ) to give a calibration range from 0 to $40 \mathrm{ng} \mathrm{L}^{-1}$. The spiked samples were left to stand for 30 minutes to equilibrate before extraction commenced.

\subsection{Sorptive extraction with sequential salting out}

\subsubsection{In-house developed sorptive PDMS sampler}

For the sorptive extraction of analytes from water matrices a cheap, easy to use, solvent free, disposable sampler was made in-house (Fig. 2A). The sampler $(0.03 \pm 0.002 \mathrm{~g})$ was fashioned (as described by Naudé et al. (2015)) by forming a loop with a $10.5 \mathrm{~cm}$ length of a silicone elastomer medical grade tubing $(0.64 \mathrm{~mm}$ OD $\times 0.3 \mathrm{~mm}$ ID, Sil-Tec, Technical Products, Georgia, USA) [13]. The ends were joined by inserting a $1 \mathrm{~cm}$ piece of uncoated silica capillary column (250 um ID) (SGE Analytical Science, Separation Scientific (Pty) Ltd, 
Roodepoort, South Africa) (Fig. 2A). A loop arrangement keeps water from entering the polydimethylsiloxane (PDMS) tubing and is convenient to handle [13]. The sorption volume of the loop was $26 \mu \mathrm{L}$ [13]. Prior to extraction, the PDMS sampling loops were conditioned using the method described by Triñanes et al. (2015) for cleaning silicone sorptive sampling disks [10].

\subsubsection{Stir bar sorptive extraction}

The in-house developed PDMS sampling loops were compared to stir bar sorptive extraction (SBSE); a commercial solvent free sorptive extraction method. SBSE using Twisters, magnetic stir bars coated with a volume of PDMS (Gerstel, Chemetrix, Midrand, South Africa), was employed to extract analytes from water. The sorption volume of the commercial stir bar was $24 \mu \mathrm{L}$ ( $0.5 \mathrm{~mm}$ film thickness, $10 \mathrm{~mm}$ length). Prior to, and between, extractions the stir bars were conditioned following the Twister reconditioning guidelines set by Gerstel. Non-volatile materials are removed by soaking the stir bars in ACN:MeOH (80:20, $\mathrm{v} / \mathrm{v}$ ) for three days. The stir bars are then placed in a clean glass desorption tube and conditioned overnight in a Gerstel tube conditioner at $280 \stackrel{\circ}{\circ} \mathrm{C}$ with $100 \mathrm{~mL} \mathrm{~min}^{-1}$ hydrogen gas flow. The clean stir bars were stored in a capped glass container.

\subsubsection{Extraction method with sequential salting out}

The multi-residue method developed and optimised by Pintado-Herrera et al. (2014) [25] for the extraction of a range of contaminants, including EDCs, fragrances and pesticides, from aqueous matrices using SBSE was adapted as a sorptive extraction method to compare the commercial sampler to the in-house prepared sampler. Pintado-Herrera et al. (2014) found that the optimized conditions for SBSE are an agitation time of 5 hours, addition of $10 \%$ $\mathrm{NaCl}, 10 \mathrm{~mm}$ length Twister stir bars and no addition of methanol [25].

Salt $(\mathrm{NaCl})$ was added sequentially using the method outlined by Ochiai et al. (2008) [15]. Water samples $(500 \mathrm{~mL})$ were placed in Schott glass bottles. A sorptive sampler (Twister stir bar or PDMS loop) was added to the sample and the opening of the bottle was sealed with aluminium foil and closed with a screw cap. Stirring commenced for 5 hours at room temperature. Agitation was achieved using magnetic stirrer plates; stirring at a rate of $1000 \mathrm{rpm}$ and $300 \mathrm{rpm}$ for the Twister stir bars and PDMS loops, respectively. It is 
imperative that the PDMS loop sampler is submerged in the water matrix and that a vortex is seen during stirring to ensure efficient extraction. The PDMS loop was secured with a stainless steel wire on a glass stirrer bar (Spinbar Pyrex magnetic stir bar, size $2.54 \mathrm{~cm} \times$ $0.95 \mathrm{~cm}$, Sigma-Aldrich, USA) in order to keep the loop immersed in the water sample. A glass stir bar was used for agitation during the PDMS loop extraction to minimize the adsorption of analytes onto the magnetic stir bar as would have been the case when using a polytetrafluoroethylene (PTFE) stir bar.

After the first extraction, the sampler (commercial or in-house made) was removed with a clean stainless steel tweezer, dried with a lint free tissue and placed in a $17.8 \mathrm{~cm}$ long glass desorption tube (for desorption in a TDS) or in a capped glass vial (for direct desorption in a GC inlet). The desorption tube or glass vial containing the samplers was temporarily stored at $4 \stackrel{\circ}{\circ}$. After removal of the first sampler, $10 \% \mathrm{NaCl}(\mathrm{w} / \mathrm{v})(50 \mathrm{~g}$ per $500 \mathrm{~mL}$ sample) was dissolved in the water sample and a second sampler was placed in the sample. A second extraction was performed under the same conditions as for the first extraction. After the second extraction was completed the sampler (commercial or in-house made) was removed with a clean stainless steel tweezer, dried with a lint free tissue and placed in the glass desorption tube or capped glass vial which contained the first Twister stir bar or loop [15]. PDMS sampler loops stored in the glass vial were subsequently transferred into a glass inlet liner for thermal desorption (TD) directly in an inlet of a GC. For comparison, Twister stir bar samplers or PDMS loops were placed in a glass TDS tube for thermal desorption in a commercial TDS.

2.5. Instrumentation

\subsubsection{Thermal desorption}

Direct thermal desorption of analytes from PDMS loops in the inlet liner of a GC inlet was compared to desorption of analytes from PDMS loops or commercial stir bars in a Gerstel thermal desorber system (Chemetrix, Midrand, South Africa). 


\subsubsection{Desorption in a TDS}

The glass desorption tube containing the sorptive samplers (Twister stir bars or PDMS loops) was placed in a Gerstel TDS for thermal desorption into a LECO Pegasus 4D GC×GC-TOFMS (LECO Africa (Pty) Ltd., Kempton Park, South Africa). Compounds concentrated onto the samplers were thermally desorbed by heating the samplers in the TDS from $30^{\circ} \mathrm{C}$ (hold 3 minutes) at $60^{\circ} \mathrm{C} \min ^{-1}$ to $280^{\circ} \mathrm{C}$ (hold 5 minutes) with a desorption flow rate of $100 \mathrm{~mL} \mathrm{~min}^{-1}$ at a vent pressure of $10 \mathrm{psi}$ (helium 5.0, Afrox, South Africa). The TDS transfer line temperature was $300^{\circ} \mathrm{C}$. The desorbed analytes were cryogenically focused at $100^{\circ} \mathrm{C}$ using liquid nitrogen (Afrox, South Africa) in a cooled injection system (CIS) (Gerstel CIS 4) with an empty, baffled, deactivated glass liner. After desorption a splitless injection (purge on at 1.5 minutes, purge flow $30 \mathrm{~mL} \mathrm{~min}^{-1}$, solvent vent mode) was performed by heating the $\mathrm{CIS}$ from $-100{ }^{\circ} \mathrm{C}$ at $10^{\circ} \mathrm{C} \mathrm{s}^{-1}$ to $280^{\circ} \mathrm{C}$ and held there for the duration of the GC run (81.07 minutes total run time).

\subsubsection{Desorption directly in an inlet liner of a GC}

The PDMS loops were inserted into a splitless glass inlet liner (Agilent Chemetrix, Midrand, South Africa) of a GC×GC-TOFMS (Fig. 2B). The gas flow to the inlet was switched off, and after removing the inlet nut the liner with loops was placed into the GC inlet (Fig. 2C), the inlet nut and gas flow were restored and the run was started. The loops were desorbed at $250^{\circ} \mathrm{C}$ with a splitless time of $1 \mathrm{~min}$ and an inlet purge gas flow of $20 \mathrm{~mL} \mathrm{~min}^{-1}$. After analysis, the hot inlet liner was manually removed from the GC inlet using a pair of tweezers (Fig. 2C) and the next batch of PDMS loops was inserted for desorption (Fig. 2B). 


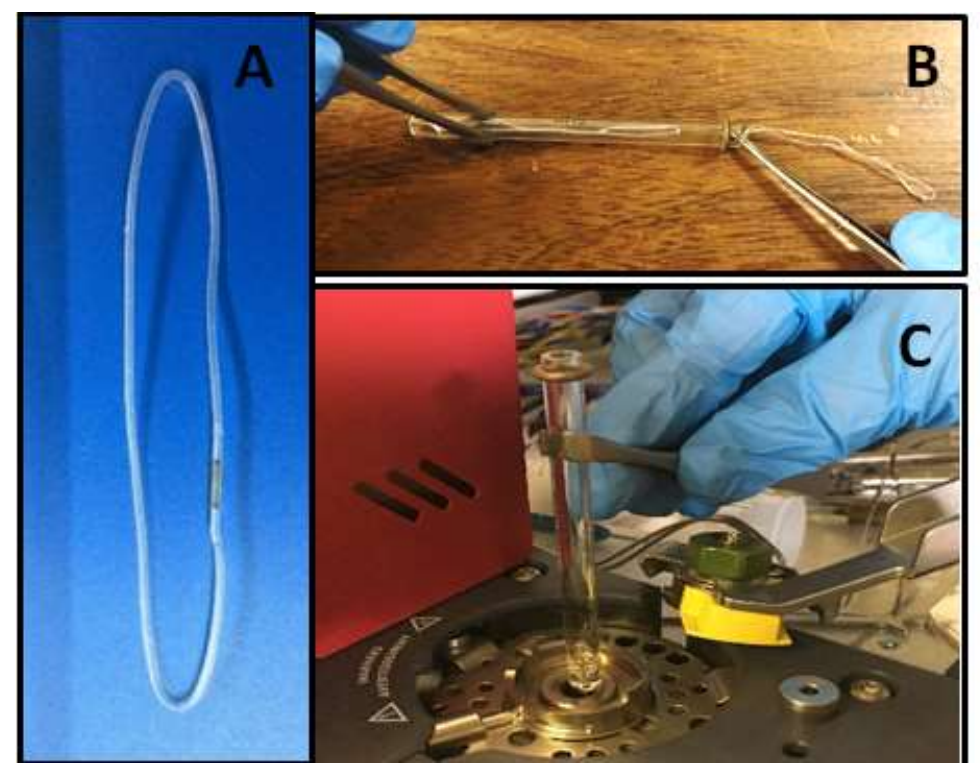

Figure 2. A) Disposable PDMS sampler loop. B) Insertion of the PDMS sampler loops (after sequential salting out extraction) in a GC inlet liner for direct thermal desorption in the inlet of a GC. C) Positioning (using tweezers) of a GC inlet liner pre-loaded with PDMS sampler loops into an inlet of a GCxGCTOFMS for direct thermal desorption of the PDMS sampler loops. After analysis, the liner is removed with a pair of tweezers and loaded with the next batch of PDMS loops.

\subsubsection{GC $\times$ GC-TOFMS}

Separation of compounds was performed on a LECO Pegasus 4D GC $\times$ GC-TOFMS system. The system consists of an Agilent ${ }^{\odot} 7890$ GC (LECO Africa (Pty) Ltd., Kempton Park, South Africa) modified to contain a dual stage modulator and secondary oven. Nitrogen gas cooled with liquid nitrogen was used for the cold jets and synthetic air for the hot jets. The primary column was connected to the secondary column with a presstight column connector (Restek, Bellefonte, PA, USA). ChromaTOF software (version 4.50.8.0 optimised for Pegasus, LECO Africa (Pty) Ltd.) was used to operate the instrument and for data capturing and processing. A column set consisting of a proprietary Crossbond phase Rtx-CLPesticides II $30 \mathrm{~m} \times 0.25 \mathrm{~mm}$ ID $\times 0.2 \mu \mathrm{m}$ film thickness (fused silica) as the primary column ( ${ }^{1} \mathrm{D}$ ) joined to a Rxi-17Sil MS $1 \mathrm{~m} \times 0.25 \mathrm{~mm}$ ID $\times 0.25 \mu \mathrm{m}$ film thickness secondary column ( ${ }^{2} \mathrm{D}$ ) (Restek, Bellefonte, PA, USA) was used. The primary oven temperature programme was $70^{\circ} \mathrm{C}$ (hold for $1.5 \mathrm{~min}$ ) at $10^{\circ} \mathrm{C} \mathrm{min}^{-1}$ to $300^{\circ} \mathrm{C}$ (hold for $10 \mathrm{~min}$ ). The $\mathrm{GC}$ run time was $34.5 \mathrm{~min}$. The secondary oven was offset by $+10^{\circ} \mathrm{C}$ relative to the primary oven. The modulator 
temperature was offset $15^{\circ} \mathrm{C}$ relative to the second oven temperature. The modulation period was 3 seconds with a hot pulse time of 0.75 seconds. The carrier gas (helium 5.0, Afrox, South Africa) flow rate was $1.4 \mathrm{~mL} \mathrm{~min}^{-1}$ in the constant flow mode. The MS transfer line temperature was set at $300^{\circ} \mathrm{C}$. The ion source temperature was $230^{\circ} \mathrm{C}$, the electron energy was $70 \mathrm{eV}$ in the electron ionisation mode $(\mathrm{El}+)$, the data acquisition rate was 100 spectra s ${ }^{-1}$, the mass acquisition range was $40-650$ Daltons, and the detector voltage was set at $1570 \mathrm{~V}$.

\subsection{Method validation}

The performance of each method was evaluated by plotting multi-level matrix matched calibration curves using at least five concentration levels of the target analytes. Linear regression analyses were performed. LODs, LOQs, \% RSD (method precision) and \% recovery (method accuracy) were determined using calibration curves. Limits of detection (LODs) and limits of quantification (LOQs) were calculated as those concentrations giving a signal to noise ratio $(\mathrm{S} / \mathrm{N})$ of 3 and 10 , respectively. Between day analysis utilising three replicates $(n=3)$, one spike per day over three days, was done to determine the method accuracy (\% recovery) and precision (\% relative standard deviation (RSD)). De-ionised water (50 mL) spiked with $1 \mathrm{ng}\left(1 \mu \mathrm{L}\right.$ of a $1 \mathrm{ng}_{\mu \mathrm{L}^{-1}}$ mixed working standard solution in acetone) of each target analyte was used for the replicate extractions.

A statistical comparison between the means of the three different methods, (1) PDMS loop TD in GC inlet, (2) PDMS loop with TDS and (3) SBSE with TDS, was done. Statistical analysis was performed by using analysis of variance (ANOVA F-test) set at a $95 \%$ level of confidence (LOC). Any difference between methods was considered significant when $F$ calculated ( $F$ calc) was greater than $F$ critical.

\section{Results and discussion}

\subsection{Target analytes}

Ten analytical reference standards were selected for method validation and comparison of the three methods. The goal of selecting these compounds was to simulate 
the variation in chemical characteristics and classes one would expect when detecting micropollutants in real world samples. The analytes selected include a pharmaceutical, a personal care product (fragrance), pesticides and an alkylphenol. These analytes represent a range of heterogeneous compounds with a selection of log $K_{\text {ow }}\left(K_{o w}\right.$ being the octanol-water partitioning coefficient) values (Fig. 1). The $K_{\text {ow }}$ values were an important consideration as the sole parameter regulating the recovery of an analyte from the sample is the ratio between the partitioning constant $K_{\mathrm{ow}}$ and the phase ratio $\beta$ (which equals Volume WATER $_{\text {Volume }}$ PDMS $_{\text {) of }}$ the PMDS sorbent and the water sample [9]. This applies because the partitioning coefficients between PDMS and water $\left(K_{\mathrm{PDMS} / \mathrm{W}}\right)$ are approximately proportional to octanolwater partitioning coefficients $\left(K_{\mathrm{ow}}\right)$ [5]. In order to increase the recoveries of more polar compounds $\left(\log K_{o w}<4\right)$ onto the PDMS salt was added sequentially enabling the sorptive methods to be applied to a larger range of compounds (polar and apolar).

\subsection{Method validation and comparison}

\subsubsection{Linearity}

The linearity of all three methods ((1) PDMS loop with direct thermal desorption in the inlet liner of a GC (TD-GC $\times$ GC-TOFMS), (2) PDMS loop with TD using a commercial thermal desorber system (TDS-GC $\times$ GC-TOFMS) and (3) SBSE with TDS-GC $\times$ GC-TOFMS is given in Table 1. Good linearity was demonstrated overall. The goodness of fit $\left(R^{2}\right)$ for all analytes was above 0.946 . However, for most analytes, the $R^{2}$ was $>0.98$.

Poor linearity $\left(R^{2}=0.946\right)$ for metolachlor using SBSE with TDS-GC $\times$ GC-TOFMS is likely due to analyte carry-over from the Twister stir bar from analysis to analysis. Very high method blanks were observed for metolachlor for SBSE (peak area: 292579) compared to the PDMS loop (peak area: 75935). Metolachlor shows an increase in the intercept value on the $y$-axis of the SBSE calibration curve compared to the PDMS loop calibration curves. Reconditioning of the Twister stir bars between extractions proved to be inadequate for the removal of metolachlor from the PDMS thereby demonstrating the advantage of a disposable sampler. 
Comparable calibration regression linearities were observed for the PDMS loop

methods and SBSE (excluding 4-tert-amylphenol, discussion to follow) (Table 1).

Comparable calibration regression linearities were also observed for the desorption of PDMS

loops using the two thermal desorption methods, i.e., GC inlet TD and the Gerstel TDS (Table

1).

Table 1. Matrix matched calibration: Linearity, LODs and LOQs of the PDMS loop with GC inlet TD-

GC $\times$ GC-TOFMS, PDMS loop with TDS-GC $\times$ GC-TOFMS and SBSE with TDS-GC $\times$ GC-TOFMS

methods.

\begin{tabular}{|c|c|c|c|c|c|c|c|}
\hline \multirow[t]{2}{*}{ Analyte } & \multirow{2}{*}{$\begin{array}{c}\text { Quantifi } \\
\text { cation } \\
\text { Ion }(m / z)\end{array}$} & \multicolumn{4}{|c|}{ Linearity } & \multirow[b]{2}{*}{$\begin{array}{l}\text { LODs } \\
\left(\text { ng L }^{-1}\right)\end{array}$} & \multirow[b]{2}{*}{$\begin{array}{l}\text { LOQs } \\
\left(\mathrm{ng} \mathrm{L}^{-1}\right)\end{array}$} \\
\hline & & Range (ng L-1) & $\begin{array}{l}\text { Number } \\
\text { of points }\end{array}$ & Regression Equation $^{a}$ & $\mathbf{R}^{2}$ & & \\
\hline \multicolumn{8}{|c|}{ PDMS sampling loop TD directly in GC inlet liner } \\
\hline 4-tert-Amylphenol & 135 & $0-40$ & 6 & $y=14483 x+7650.6$ & 0.970 & 0.098 & 0.33 \\
\hline Atrazine & 200 & $0-40$ & 6 & $y=22074 x+4667.5$ & 0.970 & 0.076 & 0.25 \\
\hline Lindane & 181 & $0-40$ & 8 & $y=111369 x+4865.9$ & 0.992 & 0.0088 & 0.029 \\
\hline Terbuthylazine & 173 & $0-40$ & 5 & $y=35518 x+19749$ & 0.956 & 0.0017 & 0.0055 \\
\hline Caffeine & 194 & $0-40$ & 5 & $y=46921 x+16978$ & 0.970 & 0.026 & 0.085 \\
\hline Terbutryn & 226 & $0-40$ & 6 & $y=64739 x+1906.5$ & 0.998 & 0.012 & 0.039 \\
\hline Chlorpyrifos & 97 & $0-40$ & 6 & $y=239299 x-8809.4$ & 0.995 & 0.036 & 0.12 \\
\hline Metolachlor & 162 & $0-40$ & 6 & $y=183665 x+71499$ & 0.978 & 0.0010 & 0.0030 \\
\hline Musk ketone & 279 & $0-40$ & 8 & $y=34561 x+798.07$ & 0.998 & 0.0013 & 0.0043 \\
\hline Bifenthrin & 181 & $0-40$ & 6 & $y=92871 x+3151.1$ & 0.990 & 0.032 & 0.11 \\
\hline \multicolumn{8}{|c|}{ PDMS sampling loop TD using the TDS } \\
\hline 4-tert-Amy|phenol & 135 & $0-20$ & 5 & $y=964938 x+52699$ & 0.993 & 0.0010 & 0.0030 \\
\hline Atrazine & 200 & $0-40$ & 11 & $y=12368 x+2953.1$ & 0.969 & 0.018 & 0.059 \\
\hline Lindane & 181 & $0-40$ & 8 & $y=124184 x+12351$ & 0.992 & 0.015 & 0.050 \\
\hline Terbuthylazine & 173 & $0-40$ & 6 & $y=25306 x+19080$ & 0.987 & 0.0043 & 0.014 \\
\hline Caffeine & 194 & $0-20$ & 5 & $y=59473 x+12728$ & 0.956 & 0.0040 & 0.013 \\
\hline Terbutryn & 226 & $0-40$ & 7 & $y=52171 x+4323.1$ & 0.993 & 0.021 & 0.069 \\
\hline Chlorpyrifos & 97 & $0-40$ & 7 & $y=369184 x-6267.9$ & 0.983 & 0.058 & 0.19 \\
\hline Metolachlor & 162 & $0-20$ & 5 & $y=166612 x+132149$ & 0.991 & 0.0010 & 0.0030 \\
\hline Musk ketone & 279 & $0-40$ & 10 & $y=47780 x+50.037$ & 0.961 & 0.018 & 0.059 \\
\hline Bifenthrin & 181 & $0-40$ & 6 & $y=112296 x+6140.8$ & 0.978 & 0.059 & 0.20 \\
\hline \multicolumn{8}{|c|}{ SBSE TD using the TDS } \\
\hline 4-tert-Amylphenol & 135 & - & - & Detected $^{b}$ & $\mathrm{~N} / \mathrm{A}$ & $\mathrm{N} / \mathrm{A}$ & N/A \\
\hline Atrazine & 200 & $0-20$ & 7 & $y=24981 x+381.96$ & 0.966 & 0.015 & 0.049 \\
\hline Lindane & 181 & $0-40$ & 8 & $y=149944 x+6304.4$ & 0.993 & 0.010 & 0.032 \\
\hline Terbuthylazine & 173 & $0-20$ & 5 & $y=65341 x+4065$ & 0.994 & 0.0090 & 0.030 \\
\hline Caffeine & 194 & $0-10$ & 6 & $y=116730 x+18417$ & 0.988 & 0.0069 & 0.023 \\
\hline Terbutryn & 226 & $0-20$ & 8 & $y=99008 x+650.69$ & 0.966 & 0.011 & 0.036 \\
\hline Chlorpyrifos & 97 & $0-40$ & 8 & $y=262613 x+6597.3$ & 0.997 & 0.019 & 0.062 \\
\hline Metolachlor & 162 & $0-40$ & 5 & $y=188125 x+320099$ & 0.946 & 0.0010 & 0.0033 \\
\hline Musk ketone & 279 & $0-40$ & 9 & $y=44998 x+465.67$ & 0.999 & 0.014 & 0.048 \\
\hline Bifenthrin & 181 & $0-40$ & 6 & $y=17994 x+587.09$ & 0.983 & 0.19 & 0.63 \\
\hline
\end{tabular}

3.2.2. Limit of detection (LOD) and limit of quantification (LOQ)

The LODs and LOQs for the three methods (1) PDMS loop TD in GC inlet liner, (2)

PDMS loop with TDS and (3) SBSE with TDS are given in Table 1. LODs ranged from 0.0010

$\mathrm{ng} \mathrm{L^{-1 }}$ for metolachlor (in-house and commercial sorptive extraction methods) to $0.19 \mathrm{ng} \mathrm{L}^{-1}$ 
for bifenthrin (SBSE) and LOQs ranged from $0.0030 \mathrm{ng} \mathrm{L}^{-1}$ for metolachlor (in-house and commercial sorptive extraction methods) to $0.63 \mathrm{ng} \mathrm{L}^{-1}$ for bifenthrin (SBSE). Measurements at ultra-trace levels (ppt to ppq) of the target analytes are realised for the in-house and commercial methods using thermal desorption with GCxGC-TOFMS. The LODs and LOQs are significantly lower than the levels required by the EU directive (pesticides $100 \mathrm{ng} \mathrm{L}^{-1}$, total pesticides $200 \mathrm{ng} \mathrm{L}^{-1}$ ), WHO guidelines (atrazine $100 \mu \mathrm{g} \mathrm{L}^{-1}$, chlorpyrifos $30 \mu \mathrm{g} \mathrm{L}^{-1}$, lindane 2 $\mu \mathrm{g} \mathrm{L}^{-1}$, metolachlor $10 \mu \mathrm{g} \mathrm{L}^{-1}$, terbuthylazine $7 \mu \mathrm{g} \mathrm{L}^{-1}$ ) and US EPA regulations (atrazine 0.003 $\mathrm{mg} \mathrm{L}^{-1}$, lindane $0.0002 \mathrm{mg} \mathrm{L}^{-1}$ ) for drinking water quality [26-28].

Table 2: Accuracy (\% Recovery) and precision (\% RSD) determined in triplicate at $1 \mathrm{ng}$ per $50 \mathrm{~mL}(20$ $n g \mathrm{~L}^{-1}$ ) for the respective sorptive extraction (disposable PDMS sampler vs. SBSE) and TD (GC inlet vs. TDS) methods and GC $\times$ GC-TOFMS.

\begin{tabular}{|c|c|c|c|c|c|c|}
\hline \multirow{2}{*}{ Analyte } & \multicolumn{2}{|c|}{ PDMS $^{\mathrm{a}}$ Loop in GC Inlet ${ }^{\mathrm{b}}$} & \multicolumn{2}{|c|}{ PDMS Loop in TDS ${ }^{c}$} & \multicolumn{2}{|c|}{ SBSE $^{\mathrm{d}}$ in TDS } \\
\hline & $\overline{\mathbf{x}} \pm \sigma_{\% \operatorname{Rec}(n=3)}$ & \% RSD & $\overline{\mathbf{x}} \pm \sigma_{\% \operatorname{Rec}(n=3)}$ & \% RSD & $\overline{\mathbf{x}} \pm \sigma_{\% R e c}(n=3)$ & \% RSD \\
\hline 4-tert-Amylphenol & $100 \pm 11$ & 11 & $116 \pm 13$ & 11 & $\mathrm{~N} / \mathrm{A}^{\mathrm{e}}$ & $\mathrm{N} / \mathrm{A}$ \\
\hline Atrazine & $115 \pm 8$ & 6.5 & $101 \pm 27$ & 27 & $114 \pm 10$ & 8.7 \\
\hline Lindane & $121 \pm 10$ & 8.0 & $129 \pm 0.92^{\dagger}$ & 1 & $128 \pm 18$ & 14 \\
\hline Terbuthylazine & $109 \pm 10$ & 9.1 & $104 \pm 22$ & 21 & $106 \pm 3$ & 2.8 \\
\hline Caffeine & $152 \pm 84$ & 55 & $50 \pm 38$ & 76 & $23 \pm 3$ & 13 \\
\hline Terbutryn & $98 \pm 13$ & 14 & $103 \pm 17$ & 17 & $104 \pm 14$ & 14 \\
\hline Chlorpyrifos & $93 \pm 13$ & 14 & $92 \pm 8$ & 8.8 & $114 \pm 7$ & 6.2 \\
\hline Metolachlor & $120 \pm 8$ & 6.6 & $105 \pm 22$ & 21 & $104 \pm 60$ & 58 \\
\hline Musk ketone & $85 \pm 13$ & 15 & $101 \pm 25$ & 25 & $119 \pm 16$ & 13 \\
\hline Bifenthrin & $129 \pm 33$ & 26 & $93 \pm 28$ & 29 & $105 \pm 23$ & 22 \\
\hline
\end{tabular}

${ }^{a}$ PDMS polydimethylsiloxane. ${ }^{b}$ Desorbed in a GC inlet. ${ }^{\mathrm{c}}$ TDS thermal desorber system. ${ }^{\mathrm{d}} \mathrm{SBSE}$ Stir bar sorptive extraction. ${ }^{e} \mathrm{~N} / \mathrm{A}$ not applicable (method not suitable). ${ }^{\mathrm{f}} \mathrm{n}=2$ (due to an outlier value (79\%) as determined by the Dixon Q-test). 


\subsubsection{Accuracy and precision}

Accuracy (\% recovery) and precision (repeatability) for each of the methods were determined using triplicate samples and the results are presented in Table 2. Good accuracy and precision were achieved with \% recovery ranging from $85 \%$ (musk ketone) to $129 \%$ (lindane and bifenthrin) and \% RSD ranged from 1\% (lindane $(n=2))$ to $58 \%$ (metolachlor) (excluding caffeine, discussion to follow). The majority of the target analytes had a precision of better than $30 \%$ and a $\%$ recovery between 70 and $130 \%$ which falls within method guideline values for water samples (EPA guideline, 1996a) [27].

The trapping efficiency of the nonpolar PDMS phase of the loop and Twister stir bar for caffeine proved challenging due to the high polarity of caffeine $\left(\log K_{o w}=-0.55\right)$. However, two of the three recovery values for caffeine extracted with loops were unexpectedly high: 95\% (TDS) and 245\% (inlet desorb) resulting in higher \% RSD values. This was most likely due to background contamination because of the ubiquitous nature of caffeine and PDMS is prone to trap ambient molecules. A high background level was also responsible for poor precision for metolachlor with the SBSE method due to analyte carry-over on the stir bar from analysis to analysis, demonstrating the benefit of a single-use sampler, and also due to background levels present in the deionised water used as a matrix. Method blanks confirmed the presence of caffeine and metolachlor in the deionised water. Regarding accuracy the Dixon Q-test for outliers at 95\% LOC showed no outliers for caffeine and metolachlor, or for any of the target analytes for any of the methods. The only exception was for lindane when using the PDMS loop with TDS, 79\% recovery was found to be an outlier (Table 2).

Comparable accuracy was generally obtained for the in-house and commercial sorptive methodology (Table 2). To determine if there are any significant differences between the accuracy of the three methods an analysis of variance (ANOVA F-test) was done for the comparison of means (\% recovery) for (1) PDMS loop TD in GC inlet, (2) PDMS loop with TDS and (3) SBSE with TDS (Table 3). A significant difference in accuracy between the three methods at a 95\% OC for the target analytes was not found, and the loop sampler with direct desorption in an inlet of a GC may be used as an alternative to SBSE and TDS. 
Table 3. Statistical analysis (ANOVA) of target analytes: comparison of accuracy (\% Recovery $(n=3))$ between the three methods (1) PDMS loop TD in GC inlet (2) PDMS loop with TDS and (3) SBSE with TDS.

\begin{tabular}{|c|c|c|c|}
\hline \multirow[t]{2}{*}{ Analyte } & \multicolumn{2}{|c|}{$\begin{array}{c}F \text {-test }(\text { ANOVA) } \\
\text { null hypothesis: } \text { mean }_{1}=\text { mean }_{2}=\text { mean }_{3}\end{array}$} & \multirow{2}{*}{\begin{tabular}{l}
\multicolumn{1}{c}{ Significantly } \\
different at $95 \%$ level of \\
confidence, reject the \\
null hypothesis $^{\mathrm{a}}$
\end{tabular}} \\
\hline & $F$ calc & $F$ critical & \\
\hline 4-tert-Amylphenol ${ }^{b}$ & 2.536 & & No \\
\hline Terbuthylazine & 0.095 & & No \\
\hline Atrazine & 0.673 & & No \\
\hline Lindane & 0.520 & & No \\
\hline Caffeine & 4.884 & 5.143 & No \\
\hline Terbutryn & 0.110 & & No \\
\hline Chlorpyrifos & 4.699 & & No \\
\hline Metolachlor & 0.186 & & No \\
\hline Musk ketone & 0.480 & & No \\
\hline Bifenthrin & 1.304 & & No \\
\hline
\end{tabular}

${ }^{a} F$ calc $>F$ critical, reject the null hypothesis and the three methods differ significantly.

$\mathrm{b}_{\%}$ Recovery was not determined for 4-tert-amylphenol using SBSE with TDS (method not suitable); comparison for (1) PDMS loop with TDS and (2) PDMS loop TD in GC inlet.

\subsection{4-tert-Amylphenol}

Good accuracy ( $100 \pm 11 \%$ recovery) and precision (11\%RSD) were obtained for the PDMS loop desorbed in an inlet of a GC, as well as for desorption of the loop in a conventional thermal desorber unit (116 $\pm 13 \%$ recovery; $11 \%$ RSD) (Table 2). However, accuracy and precision could not be determined for the SBSE-TDS-CIS method as this method was not suitable for 4-tert-amylphenol. For SBSE, all calibration points, including the blank, gave a similar response, i.e. poor sensitivity for 4-tert-amylphenol. The reconditioning of the Twister stir bars in between sample extractions appears not to be adequate for the removal of 4-tert-amylphenol from the stir bars (SBSE blank had a peak area of 858591 vs. PDMS loop blank with a peak area of 4410.6), indicating potential activity of the phenol group with the glass substrate of the Twister stir bar during reconditioning at $280^{\circ} \mathrm{C}$. Quantification of 4-tert-amylphenol was challenging due to background levels from the deionised water used for preparing the matrix matched standards.

The desorption flow rate used for 4-tert-amylphenol is also an important consideration as TD in the GC inlet liner exhibited reduced sensitivity across the calibration range compared to the PDMS loop desorbed in the TDS (Table 1). The reduced response of 4-tert-amylphenol was likely due to the lower gas flow rate $\left(20 \mathrm{~mL} \mathrm{~min}^{-1}\right)$ in the $\mathrm{GC}$ inlet during desorption and the shorter splitless injection time of $60 \mathrm{~s}$ compared to the TDS which has a high desorption

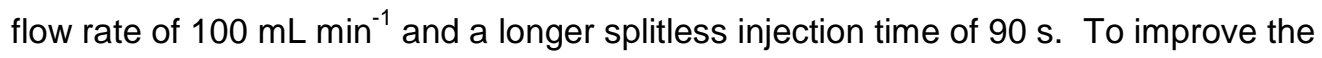


sensitivity of 4-tert-amylphenol desorbed from a loop in the inlet of a GC the splitless time may be increased and a higher gas flow rate in the pulsed splitless mode may be used.

The benefit of using a disposable PDMS loop to prevent analyte carry-over became especially evident during the quantification of 4-tert-amylphenol. Although the loop sampler appeared to be more robust for 4-tert-amylphenol due to its simpler design without the (adsorptive) underlying glass support, irrespective of the method used (loops or commercial SBSE) quantification of 4-tert-amylphenol proved challenging, possibly due to an interaction of the phenol group and exposed glass surfaces. Derivatization can improve extraction efficiency and chromatographic analysis of phenolic compounds when using PDMS [29, 30].

3.4. The PDMS loop sampler with thermal desorption directly in an inlet liner of a GC - a potential alternative to SBSE-TDS-CIS

Although the focus was on semi-volatile micropollutants acceptable peak shapes were similarly obtained for volatile compounds desorbed from the disposable sampler in an inlet liner of a GC. Figure 3 depicts benzene detected in surface water from the Albasini Dam, Limpopo Province, South Africa using the loop sampler with desorption in a GC injector (Fig. 3A) and SBSE-TDS-CIS (Fig. 3B). The peak width at half height of benzene desorbed from the PDMS loop sampler directly in the inlet liner of a GC was $0.060 \mathrm{~s}$ compared to 0.037 $s$ for SBSE-TDS-CIS. Thermal focusing of volatile compounds desorbed from the loop sampler in an inlet of a GC may be improved by lowering the GC oven start temperature from $70{ }^{\circ} \mathrm{C}$ to $35^{\circ} \mathrm{C}$ (to avoid using cryogenics) and by modification of the splitless time and inlet flow. However, even at an initial GC oven temperature of $70^{\circ} \mathrm{C}$ and a splitless time of $1 \mathrm{~min}$ the peak widths of volatile compounds are satisfactory. The peak widths of benzene are comparable to that of the semi-volatile compounds, for example the peak width for lindane was $0.059 \mathrm{~s}$ for the loop sampler with GC inlet desorption, and $0.060 \mathrm{~s}$ for SBSE-TDS-CIS.

Thermal focusing of the volatile compounds desorbed from the loop sampler directly in an inlet of a GC was surprisingly good. This we ascribe to the very efficient heating of the loop sampler in the regular $\mathrm{GC}$ inlet due to the low thermal mass (low volume $26 \mu \mathrm{L}=30 \mathrm{mg}$ 
PDMS loop sampler) of the silicone rubber tubelet without having an underlying glass support and metal rod as is the case for the Twister (200 mg Twister stir bar). Although we did not test desorption of a twister in an inlet of a GC, broader peak shapes for volatile compounds are anticipated due to the higher thermal mass of the Twister (by a factor of seven) compared to the lower mass of the loop sampler.

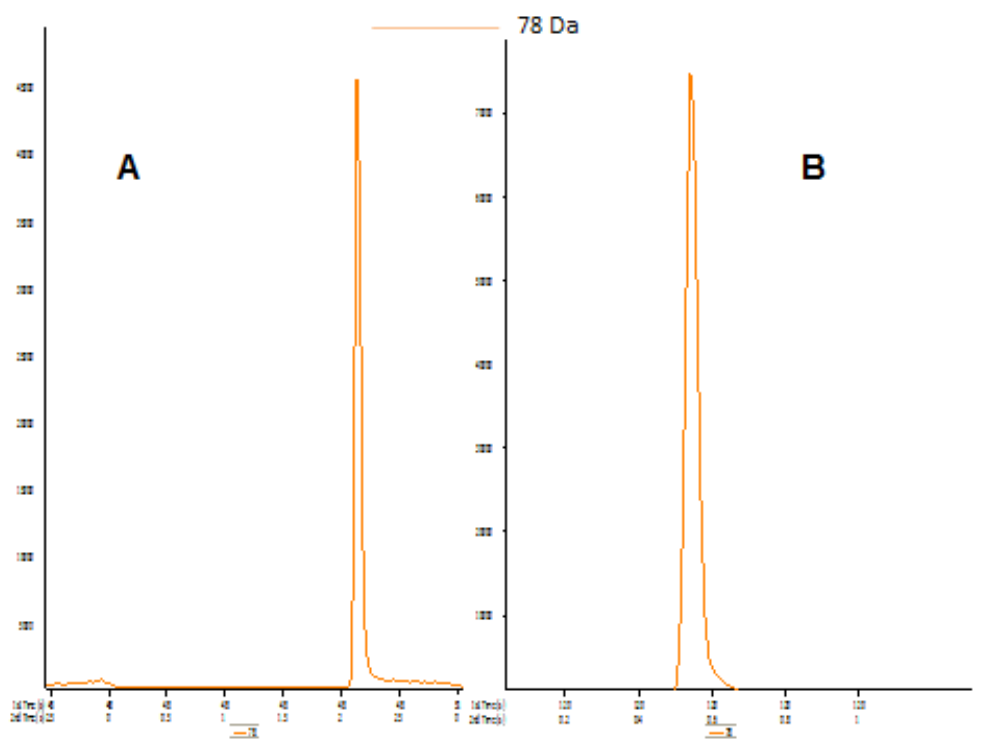

Figure 3. First dimension reconstructed ion chromatogram (78 Da) of benzene detected in surface water from the Albasini Dam, Limpopo Province, South Africa extracted with a (A) loop sampler followed by direct desorption of the sampler in the inlet liner of a GC (2016) and with (B) SBSE-TDS-CIS (2015). Thermal focusing of volatile compounds desorbed from the PDMS loop sampler in a GC inlet is comparable to that of SBSE-TDSCIS. (Different $\mathrm{X}$-axis scales are due to $\mathrm{GC}$ column maintenance).

It was demonstrated that the PDMS loop may be used as an alternative to SBSE for the extraction of water. The PDMS loop is considerably cheaper than the SBSE Twister (USD 0.76 per loop vs. USD 58.76 for a Twister). As is the case for the Twister the loop is also reusable (with appropriate conditioning in between extractions for both samplers). However, the low cost of the PDMS loop sampler allows for disposal of the sampler after a single extraction. The single-use, disposable PDMS loop sampler thus ensures the elimination of potential analyte carry-over between sample extractions. 
Additionally, it was shown that PDMS loops may be thermally desorbed directly in the inlet of GC as an alternative to desorption in a costly TDS. Thermal desorption directly in the inlet of a GC is an attractive substitute for desorption in a TDS as cryo-focussing is not required, thereby eliminating the need for consumable liquid nitrogen. Also, total sample run time is greatly reduced since a lengthy desorption step is not required as is the case when using the Gerstel TDS. A further cost saving related to desorbing directly in the inlet of the GC is that less carrier gas is used as desorption in the Gerstel TDS generally requires a high desorption flow rate of $100 \mathrm{~mL} \mathrm{~min}^{-1}$ carrier gas, especially for pesticides. Liners pre-loaded with PDMS loops were manually inserted into a GC inlet. However, the procedure may be automated, for example, by using an automated liner exchange system. The automated SBSE TDS or TDU systems may of course be used with the PDMS loop the loop is simply inserted into the TDS or TDU tube, instead of a GC liner. However, this system still caters for cryo-cooling of the GC inlet, the very step we achieved in eliminating by thermal desorption of the loop directly in the inlet of a GC.

The PDMS loop with direct desorption in the inlet liner of a GC×GC-TOFMS approach allowed quantitative detection of micropollutants in surface water from South Africa. Results are reported elsewhere [14]. In short, endocrine disrupting chemicals, including banned pesticides such as lindane and chlorpyrifos, were detected at $\mathrm{pg} \mathrm{L}^{-1}$ to $\mathrm{ng} \mathrm{L}^{-1}$ levels.

\section{Conclusion}

It was demonstrated that extraction using an in-house developed PDMS loop and SBSE gave results that do not differ significantly, and in the case of 4-tert-amylphenol, the loop sampler performed considerably better than SBSE. Therefore, the PDMS loop may be used as a cost effective alternative to SBSE. The re-usable loop sampler costs less than one USD to make which allows its use as a disposal extraction device after a single extraction, thereby eliminating potential analyte carry-over. In addition, it was demonstrated that the PDMS loop sampler, when desorbed directly in an inlet of a GC, gave results that do not differ significantly from a loop sampler desorbed in a commercial TDS. Thermal desorption directly in the inlet liner of the GC reduced sample introduction time and cryo-focussing was not required. We attribute the simplified sample introduction to the low thermal mass of the PDMS loop sampler which permits rapid desorption and narrow peaks for volatile and semi-volatile compounds alike, even in the splitless injection mode. 


\section{Acknowledgements}

We wish to thank Riana Bornman and Natalie Aneck-Hahn for providing the water samples, Riaan Marais for allowing us access to the water in Rietvlei Nature Reserve, David Masemula for assembling the PDMS loops, Jack Cochran for generous donations of GC columns and supplies, Peter Gorst-Allman from LECO Africa (Pty) Ltd. for assisting with the software and the National Research Foundation (NRF) for financial support.

\section{References}

[1] Y. Luo, W. Guo, H.H. Ngo, L.D. Nghiem, F.I. Hai, J. Zhang, . . X.C. Wang, A review on the occurrence of micropollutants in the aquatic environment and their fate and removal during wastewater treatment, Sci. Total Environ. 473 (2014) 619-641.

[2] J.-Q. Jiang, Z. Zhou, V.K. Sharma, Occurrence, transportation, monitoring and treatment of emerging micro-pollutants in waste water - A review from global views, Microchem. J. 110 (2013) 292-300.

[3] C. Margoum, C. Guillemain, X. Yang, M. Coquery, Stir bar sorptive extraction coupled to liquid chromatography-tandem mass spectrometry for the determination of pesticides in water samples: Method validation and measurement uncertainty, Talanta 116(0) (2013) 1-7.

[4] Z. Zhang, J. Pawliszyn, Headspace solid-phase microextraction, Anal. Chem. 65(14) (1993) 18431852.

[5] E. Baltussen, C. Cramers, P. Sandra, Sorptive sample preparation - a review, Anal. Bioanal. Chem. 373(1) (2002) 3-22.

[6] P.Q. Tranchida, M. Maimone, G. Purcaro, P. Dugo, L. Mondello, The penetration of green samplepreparation techniques in comprehensive two-dimensional gas chromatography, TrAC - Trends in Analyt. Chem. 71 (2015) 74-84.

[7] C.L. Arthur, J. Pawliszyn, Solid phase microextraction with thermal desorption using fused silica optical fibers, Anal. Chem. 62(19) (1990) 2145-2148.

[8] J. Pawliszyn, Theory of solid-phase microextraction, J. Chromatogr. Sci. 38(7) (2000) 270-278.

[9] E. Baltussen, P. Sandra, F. David, C. Cramers, Stir bar sorptive extraction (SBSE), a novel extraction technique for aqueous samples: theory and principles, J. Microcolumn Sep. 11(10) (1999) 737-747.

[10] S. Triñanes, M.T. Pena, M.C. Casais, M.C. Mejuto, Development of a new sorptive extraction method based on simultaneous direct and headspace sampling modes for the screening of polycyclic aromatic hydrocarbons in water samples, Talanta 132(0) (2015) 433-442.

[11] Y. Naudé, M.W. Van Rooyen, E.R. Rohwer, Evidence for a geochemical origin of the mysterious circles in the Pro-Namib desert, J. Arid Environ. 75(5) (2011) 446-456.

[12] Y. Naudé, E.R. Rohwer, Two multidimensional chromatographic methods for enantiomeric analysis of $o, p^{\prime}$-DDT and o, $p^{\prime}$-DDD in contaminated soil and air in a malaria area of South Africa, Anal. Chim. Acta 730 (2012) 120-126.

[13] Y. Naudé, P. Gorst-Allman, E. Rohwer, A cheap and simple passive sampler using silicone rubber for the analysis of surface water by gas chromatography-time of flight mass spectrometry, Water SA: WISA 2014-Water Innovations Special Edition 41(2) (2015) 182-188.

[14] M. Wooding, E.R. Rohwer, Y. Naudé, Determination of endocrine disrupting chemicals and antiretroviral compounds in surface water: A disposable sorptive sampler with comprehensive gas chromatography-Time-of-flight mass spectrometry and large volume injection with ultra-high performance liquid chromatography-tandem mass spectrometry, J. Chromatogr. A 1496 (2017) 122132. 
[15] N. Ochiai, K. Sasamoto, K. Hirooki, E. Pfannkoch, A Novel Extraction Procedure for Stir Bar Sorptive Extraction (SBSE): Sequential SBSE for Uniform Enrichment of Organic Pollutants in Water Samples, (2008) [cited 15/11/20]; Available from: http://www.gerstel.com/pdf/p-gc-an-200812 corrected.pdf.

[16] E. Matisová, S. Hrouzková, Analysis of endocrine disrupting pesticides by capillary GC with mass spectrometric detection, Int. J. Env. Res. Public Health 9(9) (2012) 3166-3196.

[17] C. Bicchi, C. lori, P. Rubiolo, P. Sandra, Headspace sorptive extraction (HSSE), stir bar sorptive extraction (SBSE), and solid phase microextraction (SPME) applied to the analysis of roasted arabica coffee and coffee brew, J. Agric. Food. Chem. 50(3) (2002) 449-459.

[18] C. Bicchi, C. Cordero, P. Rubiolo, P. Sandra, Stir bar sorptive extraction (SBSE) in sample preparation from heterogeneous matrices: determination of pesticide residues in pear pulp at ppb (ng/g) level, Eur. Food Res. Technol. 216(5) (2003) 449-456.

[19] B. Tienpont, F. David, C. Bicchi, P. Sandra, High capacity headspace sorptive extraction, J. Microcolumn Sep. 12(11) (2000) 577-584.

[20] J.R. Dean, Air Sampling, in: Extraction Techniques in Analytical Sciences, John Wiley \& Sons, Ltd, 2009, pp. 211-219.

[21] M.J. Gómez, S. Herrera, D. Solé, E. García-Calvo, A.R. Fernández-Alba, Automatic searching and evaluation of priority and emerging contaminants in wastewater and river water by stir bar sorptive extraction followed by comprehensive two-dimensional gas chromatography-time-of-flight mass spectrometry, Anal. Chem. 83(7) (2011) 2638-2647.

[22] P.Q. Tranchida, F.A. Franchina, P. Dugo, L. Mondello, Comprehensive two-dimensional gas chromatography-mass spectrometry: Recent evolution and current trends, Mass Spectrom. Rev. (2014).

[23] X. Shi, S. Wang, Q. Yang, X. Lu, G. Xu, Comprehensive two-dimensional chromatography for analyzing complex samples: Recent new advances, Anal. Methods 6(18) (2014) 7112-7123.

[24] L. Mondello, P.Q. Tranchida, P. Dugo, G. Dugo, Comprehensive two-dimensional gas chromatography-mass spectrometry: A review, Mass Spectrom. Rev. 27(2) (2008) 101-124.

[25] M.G. Pintado-Herrera, E. González-Mazo, P.A. Lara-Martín, Atmospheric pressure gas chromatography-time-of-flight-mass spectrometry (APGC-ToF-MS) for the determination of regulated and emerging contaminants in aqueous samples after stir bar sorptive extraction (SBSE), Anal. Chim. Acta 851(0) (2014) 1-13.

[26] WHO, Guidelines for drinking-water quality 4th edition, Geneva, Switzerland (2011) [cited 16/08/05]; Available from:

http://www.who.int/water_sanitation_health/publications/2011/dwq_guidelines/en/.

[27] EPA, US Environmental Protection Agency: Drinking Water Contaminants, [cited 16/08/04];

Available from: https://www.epa.gov/ground-water-and-drinking-water/table-regulated-drinkingwater-contaminants.

[28] EU, Drinking Water Directive (Council Directive 98/83/EC of 3 November 1998 on the quality of water intended for human consumption), Brussels, Belgium, [cited 16/08/05]; Available from: http://ec.europa.eu/environment/water/water-drink/legislation_en.html.

[29] E. Van Hoeck, F. Canale, C. Cordero, S. Compernolle, C. Bicchi, P. Sandra, Multiresidue screening of endocrine-disrupting chemicals and pharmaceuticals in aqueous samples by multi-stir bar sorptive extraction-single desorption-capillary gas chromatography/mass spectrometry, Anal. Bioanal. Chem. 393(3) (2009) 907-919.

[30] M. Kawaguchi, R. Ito, N. Sakui, N. Okanouchi, K. Saito, H. Nakazawa, Dual derivatization-stir bar sorptive extraction-thermal desorption-gas chromatography-mass spectrometry for determination of 17ß-estradiol in water sample, J. Chromatogr. A 1105(1) (2006) 140-147. 